\title{
COSMOLOGÍA, COSMOGONÍA Y TEOGONÍA EN EL POEMA DE PARMÉNIDES
}

\author{
Luis ANDRÉs BREDLOW \\ Universidad de Barcelona \\ luisbredlow@ub.edu

\section{COSMOLOGY, COSMOGONY AND THEOGONY IN PARMENIDES' POEM}

\begin{abstract}
El propósito de este artículo es ofrecer una nueva reconstrucción del sistema del mundo físico de Parménides, distinguiendo debidamente los momentos cosmológicos, cosmogónicos y teogónicos de la teoría, cuya confusión ha sido fuente principal de malentendidos en las interpretaciones anteriores. En particular, el sistema de coronas o anillos de B 12 y A 37 no representa el orden actual del universo, sino la estructura general de la materia, así como el estado inicial de la cosmogonía (sección 1), según puede inferirse también de la lectura de los fragmentos por Simplicio (sección 2). Esa distinción permitirá una reconstrucción tentativa de la cosmogonía (sección 3) y la cosmología de Parménides, cuyo rasgo más llamativo es la ubicación de las estrellas fijas por debajo del Sol y de la Luna, sostenida asimismo por Anaximandro y - como trataré de mostrar- en la cosmología del papiro órfico de Derveni (sección 4).
\end{abstract}

Palabras clave: Parménides; cosmología griega; cosmogonía; papiro de Derveni; Cicerón.
The aim of this paper is to offer a fresh reconstruction of Parmenides' system of the physical world, duly distinguishing the cosmological, cosmogonic and theogonic moments of the theory, whose confusion has been a main source of misunderstanding in earlier interpretations. In particular, the system of wreaths or bands of B 12 and A 37 does not represent the present order of the universe, but the general structure of matter, as well as the initial stage of the cosmogony (section 1), as can be substantiated also from Simplicius' reading of the fragments (section 2). This distinction will allow a tentative reconstruction of Parmenides' cosmogony (section 3) and cosmology, whose most striking feature is the position of the fixed stars below the sun and the moon, paralleled in Anaximander and - as I will try to show - in the cosmology of the orphic Derveni Papyrus (section 4).

Key words: Parmenides; Greek cosmology; cosmogony; Derveni Papyrus; Cicero.

\section{Introducción}

El sistema cosmológico y cosmogónico que exponía Parménides en la segunda parte de su poema es, después de la de Anaximandro, una de las más antiguas teorías griegas acerca del origen y de la estructura del universo que los testimonios nos dejan entrever (dada la casi impenetrable oscuridad 
que cubre los orígenes de la cosmología pitagórica, en la medida en que éstos pudieran ser contemporáneos y aun anteriores al filósofo de Elea, y dejando de lado asimismo las pocas y vagas generalidades y pormenores aislados que los doxógrafos trasmiten a nombre de Tales, Anaxímenes, Alcmeón, Jenófanes o Heraclito).

Del vasto alcance sistemático de esa teoría puede darnos una impresión aproximada Plutarco (Adu. Col. 1114b) recordando que Parménides

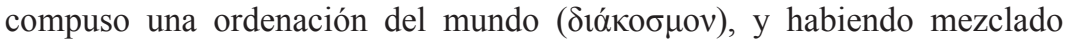
como elementos lo luminoso y lo oscuro, a partir de éstos y por medio de ellos produce todos los fenómenos; pues dejó dichas muchas cosas acerca de la Tierra, del cielo, del Sol y de la Luna, y expuso el origen de los hombres, y ... nada de los asuntos principales dejó sin decir ${ }^{1}$.

La fama de penetración y originalidad de que su cosmología gozaba es patente en la tradición que le atribuía - justificadamente o no- descubrimientos como los de la forma esférica de la Tierra $^{2}$ y la distinción de sus

${ }^{1}$ El conocimiento directo que tenía Plutarco del texto de Parménides — puesto en duda por Tarán 1965, p. 88 - ha sido convincentemente demostrado por Hershbell 1972, pp. 199203 y 207; cf. Coxon 1986, pp. 2-4.

${ }^{2}$ Diógenes Laercio IX 21 (28 A 1 DK $=$ Thphr., Phys. op. fr. 6 a [Dox. 482]): $\pi \rho \tilde{\omega} \tau o \varsigma \delta \varepsilon$

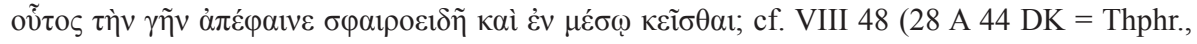

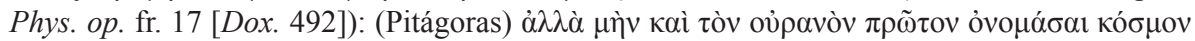

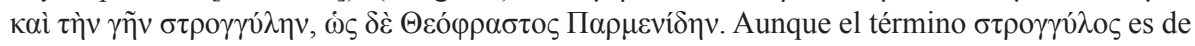
por sí ciertamente ambiguo, parece evidente que aquí se refiere en efecto a la forma esférica y no meramente a la de un disco o tambor circular (como entendieron, entre otros, Frank 1923, pp. 198-200, Heidel 1937, pp. 70-72, y Morrison 1955, p. 64), forma ésta que, como Teofrasto bien sabía, habían atribuido ya a la Tierra Anaximandro y otros (Friedländer 1928, p. 243 n. 1 = cast. 1989, p. 347 n. 1; Kahn 1960, p. 115; Burkert 1972, p. 304; en el mismo sentido ya Zeller 1892, p. 574 n. 1; para un resumen de la controversia, con amplia bibliografía, v. Untersteiner 1958, p. 92 s.; Tarán 1965, pp. 196-198, y Reale, en Zeller, Mondolfo y Reale 1967, p. 268 s.); ni tampoco la imposibilidad aparente de que Parménides dispusiera de una prueba científicamente rigurosa del hecho - como, por ejemplo, la observación de la variación de los ortos estelares entre unas latitudes y otras (Frank 1923, p. 187)- debió de impedirle formular semejante hipótesis, acaso apoyándose en otros argumentos menos científicos según los criterios actuales (Friedländer, 1. c.; Kahn 1960, p. 118), tales como la consideración metafísica de que el ser o lo-que-es ha de estar homogéneamente distribuido respecto a su centro ( $\mu \varepsilon \sigma \sigma o ́ \theta \varepsilon v$ i $\sigma o \pi \alpha \lambda \dot{\varepsilon} \varsigma \pi \alpha ́ v \tau \eta ̣$, B 8.44; la conjetura es de Furley 1987, pp. 53-56).

Por otra parte, la atribución del descubrimiento a Pitágoras o a los primeros pitagóricos —aceptada por Heath 1913, p. 64, entre otros, y aún recientemente defendida por Zhmud 


\section{cinco zonas climáticas ${ }^{3}$, el origen solar de la luz de la Luna ${ }^{4}$ la identidad del lucero vespertino y el del alba ${ }^{5}$.}

1997, p. 211 s. - proviene de una tradición doxográfica posterior a Teofrasto y merece poco crédito (véase Burkert 1972, pp. 302-306), igual que casi todas las noticias acerca de una astronomía «pitagórica» anterior a Filolao (Burkert 1972, pp. 316-322, 327-337).

${ }^{3}$ Estrabón I 94:

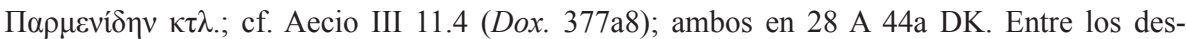
cubrimientos científicos atribuidos a Parménides, es éste el que con mayor desconfianza ha sido acogido por los estudiosos, por cuanto parece presuponer un conocimiento sumamente avanzado de los círculos celestes y de su proyección sobre la superficie terrestre (según advirtieron Reinhardt 1916, p. 147 n. 1, y, con argumentos más detallados, Dicks 1960, pp. 23-26; sobre el debate en torno a los argumentos de Reinhardt, cf. Untersteiner 1958, pp. 96-98; sobre los orígenes del concepto de las zonas climáticas y los supuestos astronómicos subyacentes, Neugebauer 1975, pp. 727, 733 n. 28). Entre los estudiosos más recientes, sólo Coxon (1986, p. 238 s.) da crédito a esa tradición doxográfica, que juzga confirmada por su propia reconstrucción del sistema de anillos de B 12; argumento que, sin embargo, no se salva de incurrir en la más flagrante circularidad, ya que dicha reconstrucción presupone, de hecho, la familiaridad de Parménides con el sistema de las zonas celestes. Con todo, queda la posibilidad de que Parménides haya concebido semejante división por razones más bien ajenas a la astronomía matemática, tal vez sencillamente imaginando el hemisferio meridional como reverso simétrico del septentrional (así Burkert 1972, p. 305 s.).

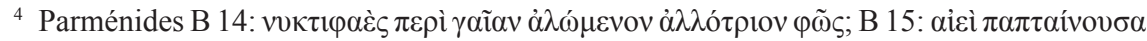

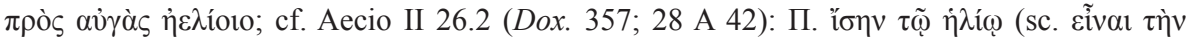

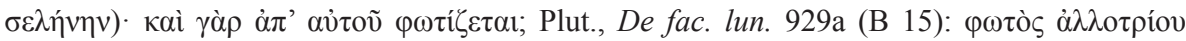
$\delta \varepsilon 0 \mu \varepsilon ́ v \eta$. A pesar de las objeciones de Tannery (1887/1930, p. 216) y Heath (1913, pp. 75-77), la atribución de este descubrimiento a Parménides ha sido mayormente aceptada por los estudiosos (Tarán 1965, p. 245 n. 40; Dicks 1970, p. 52; Vlastos 1975, p. 104; Coxon 1986, pp. 244-246; Furley 1987, p. 56); para Popper (1992 y 1998, pp. 68-104), toda la filosofía de Parménides surge de una generalización de este hallazgo crucial. Más dubitativo se muestra Guthrie 1965, p. 66; una solución de compromiso - la luz propia de la Luna es sólo prendida o atizada por la del Sol— propone O'Brien 1968; pero cf. sobre todo la pormenorizada discusión del problema en los más recientes estudios de Wöhrle 1995 y Graham 2006, pp. 179-182.

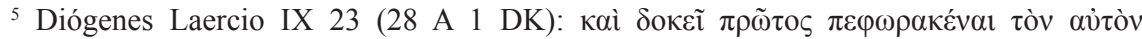

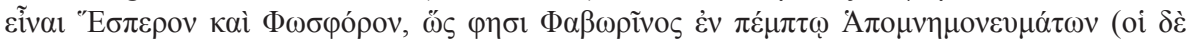

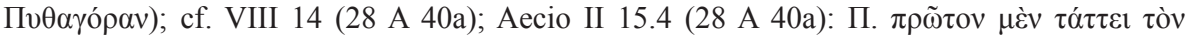

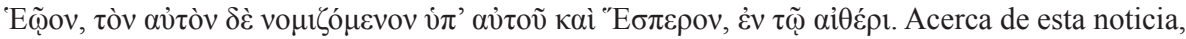
Vlastos (1975, p. 44 n. 56) observa razonablemente que «No good reason for rejecting it has ever been given» (sobre el supuesto origen pitagórico del descubrimiento, sostenido por Zeller 1892, p. 574 n. 4, y aún últimamente por Zhmud 1997, pp. 211-213, véanse las pertinentes observaciones de Burkert 1972, p. 307 s.). Ciertamente, el hecho parece haber sido familiar a los astrónomos babilonios desde el segundo milenio a. C., y no podemos excluir del todo que de ahí haya podido llegar a conocimiento de Parménides o de otros griegos, tal vez por 
Por otra parte, lo que de ese sistema del mundo ha llegado hasta nosotros a través de los escasos fragmentos literales y los —apenas algo menos fragmentarios - informes de los doxógrafos se nos muestra a todas luces demasiado exiguo y abierto a múltiples modos de interpretación (aun dejando metódicamente de lado la cuestión fundamental de la relación de esa cosmología con la Verdad que se enunciaba en la primera parte del poema) como para que parezca hacedera una reconstrucción de conjunto que vaya más allá de la mera conjetura.

Parecería, pues, ambición desmesurada y vana querer ofrecer otro intento más de solución de problema tan notoriamente irresoluble, si no fuera que el trato con esos textos (dentro de un estudio del conjunto de los restos del poema, al que vengo dedicándome, con algunas interrupciones, desde hace algo más de diez años) nos sugiere que una lectura atenta, libre hasta donde pueda de los prejuicios que han venido lastrando la mayoría de las interpretaciones modernas, puede acaso permitir una reconstrucción sorprendentemente coherente a lo menos de los lineamientos generales del sistema.

Para ello conviene tener en cuenta, ante todo, que en el único texto que recapitula el conjunto del sistema del mundo parmenídeo, el fragmento de Aecio II 7.1 (Dox. 335.3-336.3 = 28 A 37 DK, Vors. I 224.3-14), se distingue claramente no sólo la cosmogonía (Dox. 335.16-22 = Vors. 224.10-13) de la cosmología u ordenación actual del mundo (Dox. 335.22-336.3 = Vors. 224.13-14), sino que ambas aparecen nítidamente destacadas a su vez de la enigmática descripción del sistema de coronas o anillos (Dox. 335.4-16= Vors. 224.3-9), al que alude también el fragmento literal B 12.

Ahora bien, aunque nada nos garantiza de antemano que tal distinción reproduzca fielmente el orden de lo que se leía en el poema, nada nos autoriza tampoco a desecharla sin más (en efecto, veremos que en la confusión indebida de los momentos cosmológicos, cosmogónicos y teogónicos del sistema estaba la raíz de gran parte de los descarríos de las interpretaciones precedentes), de modo que será conveniente adoptarla, a falta de evidencia

\footnotetext{
vía de intermediarios fenicios; aunque tales contactos, si bien posibles en principio, no cuentan con apoyo documental alguno, por cuanto un conocimiento más o menos directo de la astronomía babilónica por parte de los griegos no parece estar atestiguado con certeza antes del siglo IV a. C. (Dicks 1970, pp. 163-175; cf. Zhmud 1997, pp. 202-209), ni tampoco las vagas semejanzas de algunos motivos del proemio parmenídeo con ciertas fórmulas rituales acadias y babilónicas — recientemente documentadas por Steele 2002- parecen suficientes para postular una influencia directa.
} 
más clara, como guía provisional de nuestro estudio. Empezaremos, por tanto, por examinar el sistema de coronas que se nos presenta, juntamente con la diosa que lo preside, en el fragmento B 12 y la primera parte del informe de Aecio (sección 1); de ahí pasaremos a una reconstrucción tentativa del orden de exposición que se seguía en esta parte del poema (sección 2) y, finalmente, a la cosmogonía y la cosmología (secciones 3 y 4 , respectivamente).

\section{Las coronas y la diosa}

El fr. B 12 aparece citado por Simplicio (In Ph. 39.14-16 para los vv. 1-3; ibíd. 31.13-17, los vv. 2-6) como sigue:

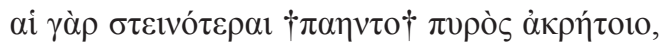

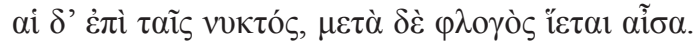

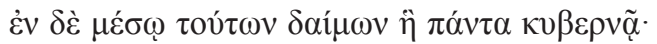

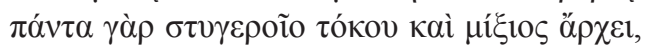

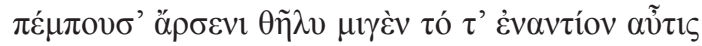

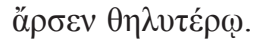

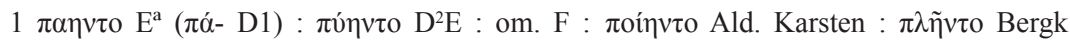

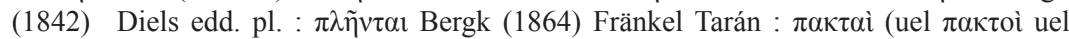

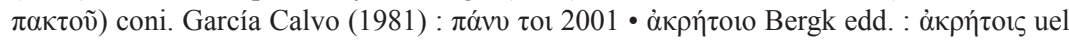

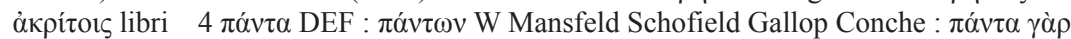

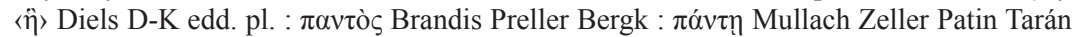

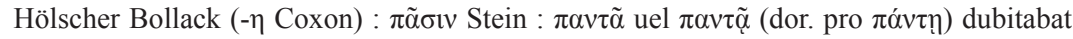

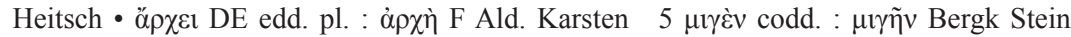
edd. pl. $\bullet \alpha \tilde{v} \tau ı \varsigma$ F edd. pl. : $\alpha \tilde{\theta} \theta 1 \varsigma$ DE.

En el primer verso, mejor que la conjetura $\pi \lambda \tilde{\eta} \nu \tau o$ de Bergk, mayoritariamente aceptada por los editores aunque flagrantemente amétrica, o la posterior corrección del mismo Bergk $\pi \lambda \tilde{\eta} v \tau \alpha \iota$ (pues en caso de «llenarse» los anillos de fuego y de noche, que podemos suponer los únicos elementos presentes en esta fase elemental de la física, quedaría ininteligible de qué, si no de fuego y noche, estaban hechos los anillos mismos), la tentativa más aceptable parece la de García Calvo, $\pi \alpha \kappa \tau \alpha i ̀$ 'trabadas', a menos que se prefiera leer $\pi \lambda \varepsilon \kappa \tau \alpha i ̀$ 'trenzadas', lo que mejor que nada correspondería al $\pi \varepsilon \rho \imath \pi \varepsilon \pi \lambda \varepsilon \gamma \mu \varepsilon ́ v \alpha \varsigma$ de Aecio y, por eso mismo, merecería nuestra preferencia, si no tuviese demasiada traza de facilior como para justificar tantas aberraciones de los copistas.

En el v. 4, aunque la conjetura de Diels $\pi \alpha ́ v \tau \omega v$ haya sido confirmada por el ms. W (ms. 3649 del Museo Histórico del Estado de Moscú, del siglo XIII; 
cf. Sider 1979), la variante mayoritaria de los manuscritos $\pi \alpha ́ v \tau \alpha$ parece aceptable con tal de entenderla como error de acentuación por $\pi \alpha v \tau \tilde{\alpha}$ o $\pi \alpha \nu \tau \tilde{\alpha}$, doricismo por $\pi$ óvṭ, como sospechaba Heitsch (1974, p. 188). Habríamos de entender, pues, aproximadamente:

Que las más estrechas están trabadas (¿trenzadas?) de fuego sin mezcla, las que siguen, de noche; y en medio salta una parte de llama.

$\mathrm{Y}$ en medio de ésas está la diosa que todo gobierna:

pues por doquier (o de todas las cosas) el parto horrendo y la mezcla inicia, mandando en lo varón lo hembruno mezclado y viceversa lo varón en lo femenino.

A esos mismos versos (y algunos más, hoy perdidos, que debían de figurar en el contexto inmediato) parece referirse el resumen de Aecio (II 7.1, Dox. 335.4-16 = Vors. I 224.3-9; añado la numeración de las frases para mayor claridad):

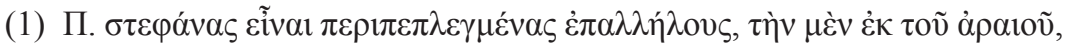

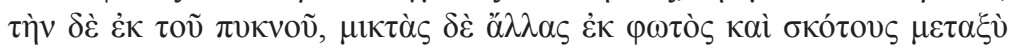

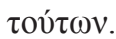

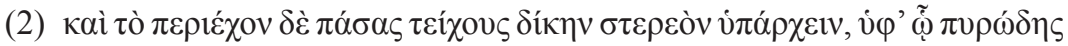

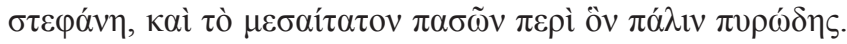

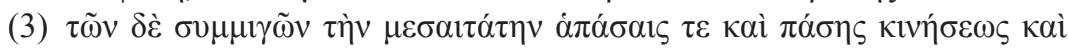


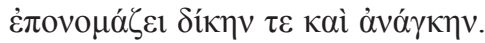

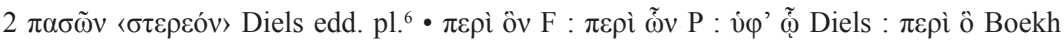

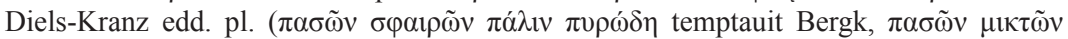

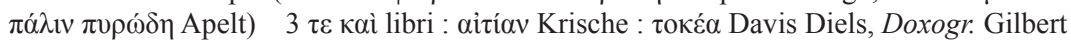

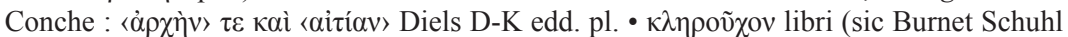

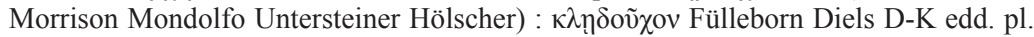

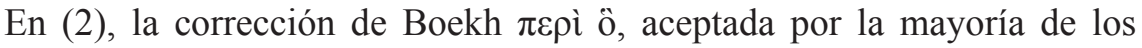
editores, restaura la gramaticalidad y ofrece un sentido bastante plausible, pero no da cuenta de cómo se haya podido originar la sustitución del neutro gramaticalmente exigido por un masculino ôv. Prefiero, por tanto, interpre-

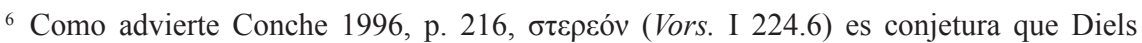
introdujo en las primeras ediciones de los Vorsokratiker y que, en las ediciones posteriores, se descuidó de señalar como tal; desde entonces, el error ha sido reproducido inadvertidamente por casi todos los demás editores. 
tar la secuencia $\pi \varepsilon \rho 10 v$ como un participio neutro $\pi \varepsilon \rho$ iòv y leer, en cambio,

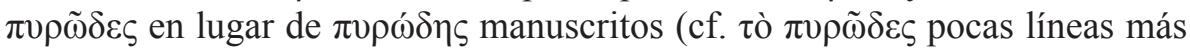

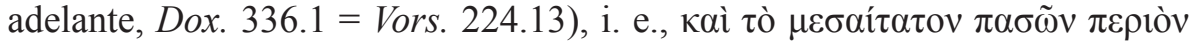
$\pi \alpha \dot{\alpha} \lambda \imath \tau^{\prime} \pi \rho \tilde{\omega} \delta \varepsilon \varsigma$.

En (3), los arreglos propuestos por los sucesivos editores parecen atestiguar más atención a lo que en este pasaje se desearía leer que a lo que el texto, indudablemente corrupto, de por sí sugiere. La solución menos

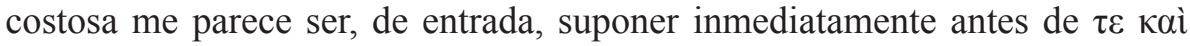

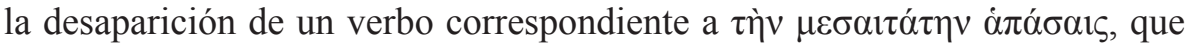
muy bien podía ser vi á́ $\chi \varepsilon \varepsilon v$, que figura al final de la oración principal; así

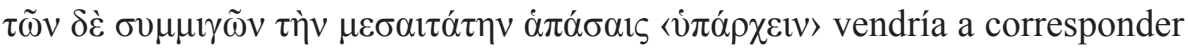

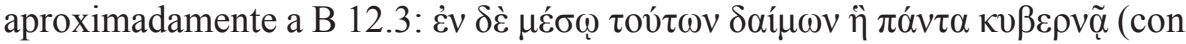
cierta duda de si en lugar de $\dot{\alpha} \pi \alpha ́ \sigma \alpha ı \zeta$ habría de leerse acaso mejor $\dot{\alpha} \pi \tilde{\alpha} \sigma v)$, mientras que el segundo miembro de la oración evoca el verso siguiente,

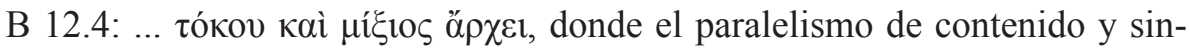
taxis, unido a la construcción de ó $\rho \chi \varepsilon 1+$ gen., sugiere una lección primitiva

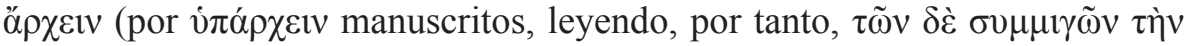

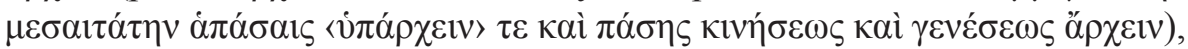

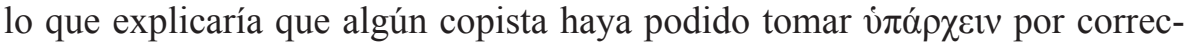

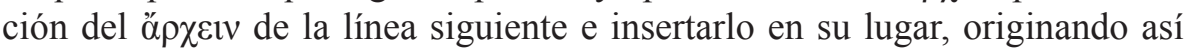
el anacoluto que presentan los manuscritos Con lo cual el sentido del pasaje sería, en suma, el siguiente:

(1) Parménides dice que hay unas coronas (o anillos) enredadas unas en torno a otras, una hecha de lo raro, otra de lo denso, y otras mixtas de luz y tiniebla en medio de aquéllas.

(2) Y que aquello que las contiene a todas, a guisa de muralla, es sólido, y debajo de ello hay una corona ígnea; y girando en torno a lo que está en medio de todas, de nuevo sustancia ígnea.

(3) Y de las mixtas, la que está en medio manda en todas ellas (¿o en todas las cosas?) y da comienzo a todo cambio y devenir; a ésa la llama también diosa gobernadora y dueña de los destinos ${ }^{7}$, Justicia y Necesidad.

${ }^{7} \mathrm{O}$ tal vez «de las llaves», si aceptamos, con la mayoría de los editores, la conjetura de

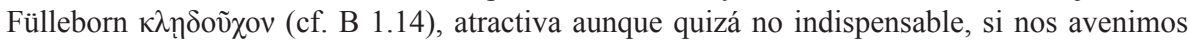
a admitir, para el $\kappa \lambda \eta \rho$ oṽ suertes', 'dueña de los destinos', no atestiguada en otra parte, pero no por ello menos conveniente a la diosa. 
No han faltado intentos de reconstruir este sistema de $\operatorname{coronas}^{8}$, aunque viciados las más de las veces por la suposición de que se trataba de una representación del universo en su estado actual (como sugería el epígrafe de Aecio Sobre la ordenación del mundo, así como la semejanza con los círculos o ruedas de fuego que en el sistema de Anaximandro representaban las órbitas astrales ${ }^{9}$ ), pese a las sensatas objeciones que Reinhardt había ya hecho valer a principios del siglo pasado.

Pues, por un lado, parece imposible hacer coincidir el esquema de las coronas aecianas con algún sistema concebible del mundo. Si con cierto esfuerzo de imaginación aún cabe identificar las coronas concéntricas con las órbitas astrales, difícilmente se ve a qué pueda corresponder la sustancia ígnea que rodea el núcleo sólido (que habríamos de suponer es la Tierra); dificultad que se resuelve, en cambio, con bastante sencillez si suponemos que la descripción de Aecio no se refiere al orden actual del mundo, sino más bien a una fase primitiva de la cosmogonía, anterior a la formación del aire y de la Vía Láctea, del Sol y de la Luna ${ }^{10}$.

Por lo demás, nada en el texto de Aecio ni en el fragmento de Parménides nos indica que hayamos de entender las coronas como órbitas astrales ni buscar en ese esquema una representación del mundo que conocemos: el texto de Aecio, según hemos ya advertido, separa claramente la descripción de las coronas (Dox. 335.4-16 = Vors. 224.3-9) de la cosmogonía (Dox. 335.16-22 = Vors. 224.10-13) y la cosmología (Dox. 335.22-336.3 = Vors. 224.13-14), momentos

\footnotetext{
${ }^{8}$ Véanse, entre otros, Tannery 1887/1930, pp. 238-240; Diels 1897, p. 104 s.; Susemihl 1899; Gilbert 1907; Heath 1913, pp. 66-74; Gigon 1945, pp. 276-283; Fränkel 1955, p. 183 s.; Morrison 1955, pp. 60-65; Untersteiner 1958, p. 83 s. y «Excursus», pp. 174-182; Hölscher 1968, p. 109; Pellikaan-Engel 1974, pp. 87-99; Coxon 1986, p. 238, y Finkelberg 1986. Una amplia sinopsis ofrece Reale, en Zeller, Mondolfo y Reale 1967, pp. 264-267, un sucinto resumen del debate también Pérez de Tudela, en Bernabé y Pérez de Tudela 2007, pp. 203-211; algunos intentos más antiguos (Berger, Döring) resume críticamente Lortzing 1902, pp. 261-264. Mención aparte merece el estudio de Bollack 1990 (cf. íd. 2006), riguroso y razonablemente despiadado para con los prejuicios que han venido tradicionalmente empañando el problema, aunque no puedo compartir todos los detalles de su interpretación.

9 Cf. Anaximandro, 12 A 11, A 21. El parecido con las «coronas» de Parménides ha sido señalado a menudo: v. p. ej. Burnet 1892/1930, p. 188, y las páginas de Untersteiner y Morrison citadas en la nota anterior.

${ }^{10}$ Cf. Aecio II 7.1, Dox. 335.17-22 = 28 A 37, Vors. I 224.10-13; II 20.8 a, Dox. $349=$ A 43 .
} 
que nada nos autoriza a confundir ${ }^{11}$; de modo que lo más razonable parece ser entender el sistema de las coronas, con Reinhardt, como una construcción puramente cosmogónica o acaso como «una especie de arquetipo (Urtypus) que se repite en infinitas variaciones en el cosmos entero así como en cada cosa particular» ${ }^{12}$.

\section{Sobre la ordenación de los fragmentos}

En el mismo sentido apuntan, por lo demás, las escuetas indicaciones de Simplicio acerca del orden en que figuraban en el poema los fragmentos por él citados. Tras haber citado los versos B 8.50-61, el comentarista introduce la cita de los primeros versos de B 12 con las palabras: $\mu \varepsilon \tau$ ' ò $\lambda \dot{i} \gamma \alpha \delta \varepsilon \dot{\varepsilon} \pi \alpha ́ \lambda \imath v$

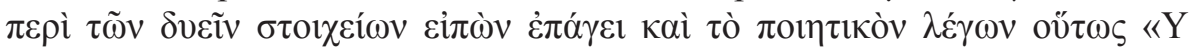
poco después de nuevo, hablando de los dos elementos, prosigue, nombrando también a lo hacedor, así» (In Ph. 39.12). El fragmento B 12 seguía, por tanto, «poco después» del final de $\mathrm{B} 8$, y por lo demás en un contexto en que se hablaba de los «dos elementos», que podía ser B 9 y poco más.

Hemos de preguntarnos, por ende, si los fragmentos B 10-11 no deberían colocarse acaso más bien después de B 12 (ordenación que siguieron, en efecto, las antiguas ediciones de Karsten y Mullach). Nótese que Simplicio

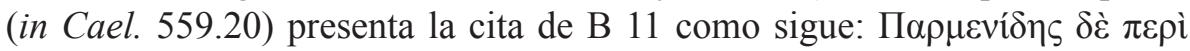

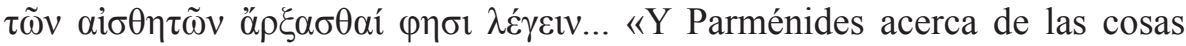
sensibles dice que empieza a explicar...». Lo cual concuerda perfectamente con la reordenación sugerida si en lo que precedía a B 11 —entre lo cual

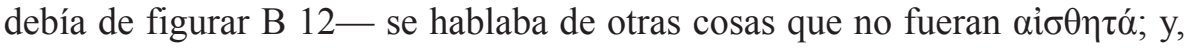
en efecto, así lo da a entender el mismo Simplicio (In Ph. 31.10) al introducir

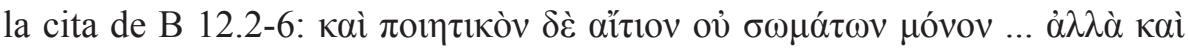

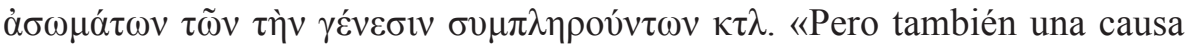
creadora, no de los cuerpos solamente ... sino también de los incorpóreos que llevan a término la génesis». Resulta patente, pues, que los versos de

${ }^{11}$ Cf. Reinhardt 1916, p. 14; en el mismo sentido Hölscher 1969, p. 107.

12 Reinhardt 1916, p. 19. Sólo desde hace pocos decenios, a más de medio siglo de su publicación, esas razonables observaciones de Reinhardt acaban siendo aceptadas por los estudiosos: el sistema de anillos representa un «esquema pre-cósmico» (Hölscher 1969, p. 108), una «estructura pre-cosmogónica» (Bollack 1990, p. 33); «Le système des couronnes ne décrit pas une structure, mais les étapes d' une genèse» (Conche 1996, p. 217). 
B 12 trataban, a juicio de Simplicio, de la causa creadora, ante todo, de «los incorpóreos» (término obviamente de Simplicio, no de Parménides), es decir, de los dioses ${ }^{13}$.

En resumidas cuentas, Simplicio contrapone expresamente los $\dot{\sigma} \sigma \omega ́ \mu \alpha \tau \alpha$ o dioses a los $\sigma \omega ́ \mu \alpha \tau \alpha=\alpha i \sigma \theta \eta \tau \dot{\alpha}$, cuya exposición se iniciaba con B 11. Parece, por tanto, que B 12 no pertenecía ni a la cosmología, ni a la cosmogonía siquiera (como suponía Reinhardt), sino a la teogonía de Parménides, o que al menos así lo entendía Simplicio ${ }^{14}$.

Del conjunto de estos pasajes, resulta bastante clara la estructura del inicio de la segunda parte del poema tal como la concibe Simplicio:

1. Los principios elementales de las cosas engendradas (B 8.53-59; B 9).

2. La causa hacedora o eficiente (B 12).

3. Los incorpóreos que llevan a término la generación, i. e., los dioses (B 13).

4. La generación de las cosas sensibles (B 11) ${ }^{15}$.

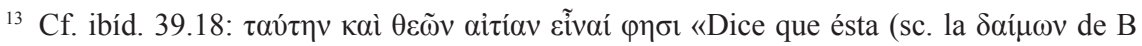
12.3) es causa también de los dioses».

${ }^{14}$ Es de notar que también Cicerón (De nat. d. I 11.28 = 28 A 37) debió de haber encon-

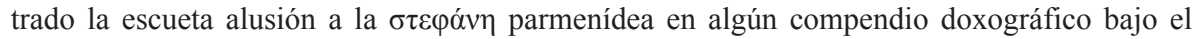
epígrafe «De los dioses» (sobre las posibles fuentes del pasaje ciceroniano, véase Untersteiner 1958, p. 84 s.): que ésta tiene poca traza de teología o teogonía, Cicerón mismo lo recalca expresamente (in quo neque figuram diuinam neque sensum quisquam suspicari potest).

${ }_{15}$ Algo semejante parece haber entrevisto Heitsch 1974, p. 188, cuando observa que B 12 ocupa una «posición mediadora» (vermittelnde Stellung) entre B 9, por un lado, y B 10, 11, 14 y 15, por otro: «Los versos [de B 12] hablan, por lo visto, del origen del mundo, colocando primero las dos formas elementales, mediante la representación de los anillos concéntricos, en un orden sistemático que luego habrá de explicar a su vez los fenómenos visibles».

No es obstáculo a esta interpretación que en otro momento (In Ph. 30.14-31.12) Simplicio parezca dar por supuesto que la exposición de las «cosas sensibles» empezaba ya con la introducción de los dos elementos en B 8.53: pues también los principios, la causa hacedora y los dioses forman parte, en cierto modo, de lo «sensible» en sentido lato, en cuanto que los

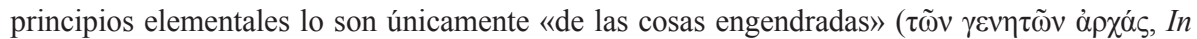

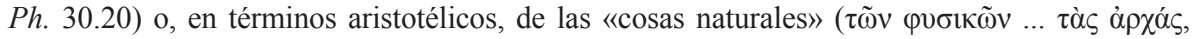
ibíd. 179.30-31), sometidas a cambio y movimiento; y en cuanto tales principios elementales

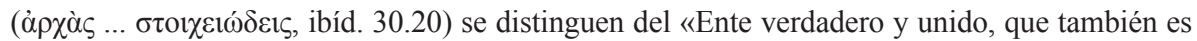

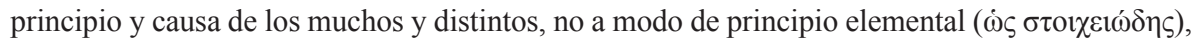
sino a modo de criador ( $\omega \varsigma$ $\pi \rho \circ \gamma \omega \gamma o ́ \varsigma$ ) de éstos» (ibíd. 38.11-13). Lo cual no impide, desde luego, que los principios, la causa hacedora y los dioses también se distingan nítidamente, por otra parte, de las cosas sensibles, de las cuales justamente son ellos principios, causa y creadores, es decir, del cosmos visible cuya formación empieza a describirse en B 11. 


\section{La cosmogonía}

Tras mencionar brevemente a la diosa gobernadora, a la que identifica con la corona mixta central (Aecio II 7.1, Dox. 335.12-16 = Vors. 224.7-9), el parafraseador pasa, de modo bastante abrupto, a la génesis del mundo actual (Dox. 335.16-22 = Vors. 224.10-13):

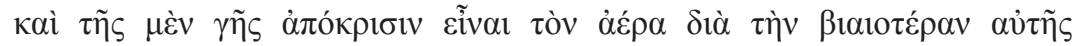

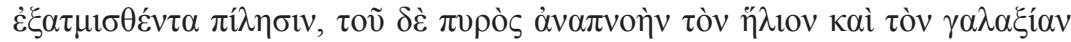

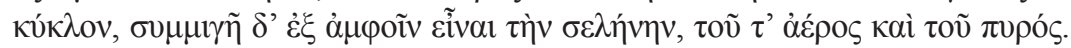

Y que secreción de la Tierra es el aire, evaporado por la compresión más violenta de ésta, mientras que exhalación del fuego son el Sol y la Vía Láctea. Mezcla de ambos es la Luna, del aire y del fuego.

Lo cual se completa con otro pasaje de Aecio, contenido en el capítulo Acer-

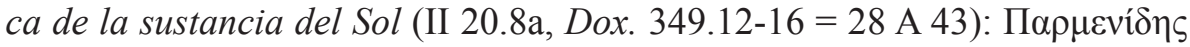

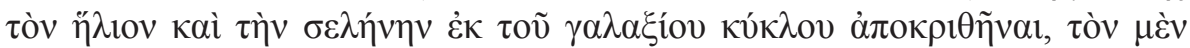

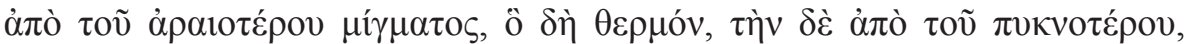

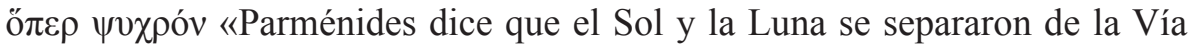
Láctea, aquél de la mezcla más rara, o sea de lo caliente, y ésta de la más densa, es decir, de lo frío», y con aquel otro, en fin, del capítulo Acerca de la Vía Láctea, de la que se anota que, según Parménides, «la mezcla de lo den-

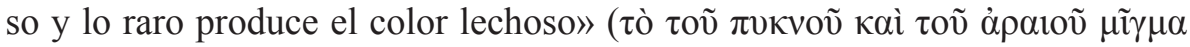

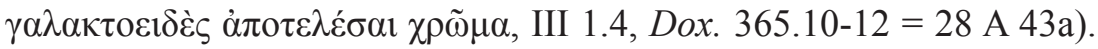

Por lo que esos escuetos retazos dejan entrever, parece que el proceso se originaba entre el núcleo sólido - aquí ya nombrado como Tierra- y la sustancia ígnea que en torno a él giraba. El aire evaporado de la Tierra acaba formando una capa esférica, en cuya zona superior se va mezclando luego una parte del fuego circundante: esa mezcla de aire y fuego es la Vía Láctea, de la que se separan a su vez el Sol, con una mayor proporción de fuego, y la Luna, con una porción relativamente mayor de aire o elemento oscuro. El resto de la capa ígnea circundante hemos de suponer ha sido despedazado entre tanto por la presión del aire, de modo que los fragmentos dispersos de fuego, comprimidos por el aire que los rodea, acaban formando los astros, que son 'condensaciones' o 'compresiones' $(\pi i \lambda \eta \mu \alpha \tau \alpha)$ del fuego ${ }^{16}$.

${ }^{16}$ Aecio, II 13.8, Dox. 342.7 = 28 A 39. Nótese el parecido con la cosmogonía de Anaximandro, en la cual los astros son los restos de una primitiva esfera de fuego que rodeaba el aire 
Parece contradecir este informe la noticia del Seudo-Plutarco (Strom. 5, en Eus., PE I 8.5, Dox. 581.4 = 28 A 22, Vors. 221.31) —aunque procedente también ésta, por lo que parece, de Teofrasto- de que Parménides $\lambda \varepsilon ́ \gamma \varepsilon ı$ $\delta \grave{\varepsilon}$

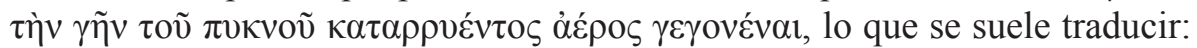
«... afirma que la tierra se formó del aire denso que se había precipitado». Aecio, por el contrario, asegura que el aire es «secreción de la tierra»: contradicción que sin mucho éxito se han esforzado en zanjar los estudiosos, sea postulando distintas especies de aire ${ }^{17} \mathrm{o}$ un proceso cíclico de precipitaciones y evaporaciones recíprocas ${ }^{18}$, sea eliminando ḋépos (Patin, Diels-Kranz y otros $^{19}$ ). Pero más bien sospecho que habremos de entender «lo denso que

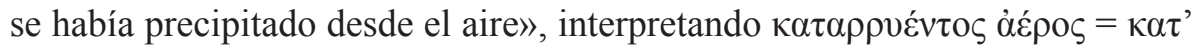
àćpos $\operatorname{\rho } v \varepsilon ́ v \tau o \zeta$, a la manera de la usual construcción con genitivo de verbos como $\kappa \alpha \tau \alpha \gamma \varepsilon \lambda \tilde{\alpha} v, \kappa \alpha \tau \eta \gamma о \rho \varepsilon \tilde{v} v, \kappa \alpha \tau \alpha \varphi \rho \circ v \varepsilon \tilde{v}$, etc., o bien, si tal construcción se

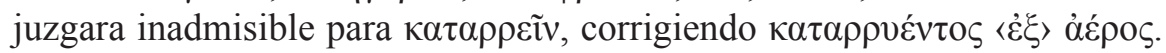

Así quedarían conciliados los testimonios de Aecio y del Seudo-Plutarco: si el aire es secreción de la Tierra y ésta se forma a su vez del elemento denso que se precipitaba desde el aire, podemos suponer un proceso simultáneo de segregación recíproca de los dos elementos, por diferenciación interna de la Noche espesa y oscura, que se divide, por efecto de compresión violenta $(\pi i ́ \lambda \eta \sigma \iota \varsigma)$, en un elemento fluido o vaporoso pero todavía oscuro llamado aire (án $\rho$ ), por un lado, y un poso de materia densa, espesa y sólida, por otro. De este modo, las tres clases de materia hasta aquí presentes (Fuego, Noche y la mezcla de ambos) se hacen cuatro por desdoblamiento del segundo en Tierra y Aire; las variadas proporciones de su mezcla resultarán suficientes para dar cuenta de la formación del mundo.

que circunda la Tierra (Anaximandro, 12 A 10, 11). Más dudosa es aquella otra noticia de Aecio (II 17.4, Dox. 346.18-20 = Test. 66 Coxon), sobre la opinión que algunas variantes manuscritas atribuyen, además de a Heraclito (con escaso o nulo fundamento), a Parménides, de que

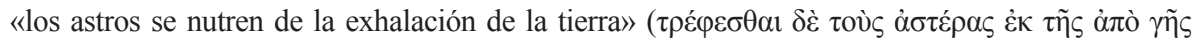
$\grave{\alpha} v \alpha \theta v \mu$ ió $\sigma \varepsilon(\omega)$ ). Si la noticia, patentemente incompatible con lo que el mismo Aecio refiere en los otros pasajes citados, tiene algún fundamento, debe de tratarse de un malentendido de algún pasaje del poema (o de algún resumen anterior) en el cual se decía tal vez que los astros se condensaron o coagularon (= $\tau \rho \varepsilon ́ \varphi \varepsilon \sigma \theta \alpha$ l, que Aecio o su fuente toma erróneamente en el otro sentido de 'nutrirse' o 'alimentarse') a causa de (es decir, bajo la presión de) las exhalaciones terrestres.

${ }_{17}$ Así, por ejemplo, Zeller 1892, p. 574 n. 2, y Bollack 1990, p. 45.

18 Diels 1897, p. 99 s.; Untersteiner 1958, p. 51.

19 P. ej. Reinhardt 1916, p. 14 n. 1; en cambio, Finkelberg 1997, p. 2 n. 4, rechaza la noticia de Aecio como «a corruption of Theophrastus' account». 


\section{El sistema del mundo}

En conclusión de su resumen, Aecio esboza someramente la ordenación actual del mundo según Parménides (II 7.1, Dox. $335.22=$ Vors. 224.13-14):

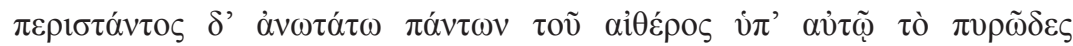

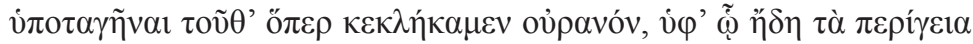

Circundante en lo más alto de todas las cosas el éter, por debajo de éste está colocado lo ígneo que llamamos cielo, e inmediatamente debajo las cosas que rodean la Tierra.

El mismo Aecio escribe, en el capítulo Sobre la disposición de los astros (II 15.4, Dox. $345.14-18=28$ A 40 a):

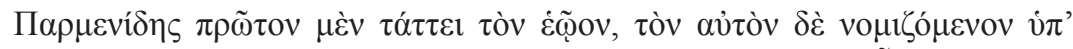

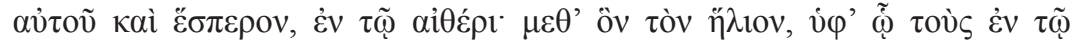

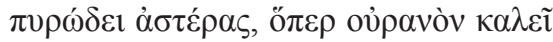

Parménides primero coloca el lucero matutino, el mismo en su opinión que el vespertino, en el éter; después de éste, el Sol, debajo del mismo los astros que están en lo ígneo que llama cielo.

Las dos enumeraciones - de las zonas celestiales, la primera, de los astros que en éstas se encuentran, la segunda - integran un cuadro coherente del orden celeste: primero, en el extremo exterior, el éter ( $\alpha i \theta \eta \dot{\rho} \rho$ ), donde se sitúa Venus y, probablemente, el Sol; luego, una zona ígnea llamada 'cielo' (oủpavós), región de los demás astros o por lo menos de las estrellas fijas; y finalmente, $\tau \grave{\alpha} \pi \varepsilon \rho i ́ \gamma \varepsilon 1 \alpha$ 'lo que rodea la Tierra'.

La mayoría de los estudiosos modernos, sin embargo, han juzgado inverosímil esa disposición, alegando las supuestas discrepancias entre ésta y los fragmentos literales ${ }^{20}$. Más bien lo contrario sugiere, sin embargo, una lectura atenta del único fragmento literal que acaso pueda arrojar alguna luz sobre el orden cósmico que en el poema se describía (B 10) ${ }^{21}$ :

${ }^{20}$ Así Tannery 1887/1930, p. 240; Zeller 1892, p. 574 s.; Gundel 1950, col. 2043, y Conche 1996, p. 214.

${ }^{21}$ En cuanto al otro fragmento cosmológico, B 11, es evidente que el orden de enumeración (Tierra, Sol, Luna, éter, la «leche celeste», Olimpo último, astros) no pretende reproducir 


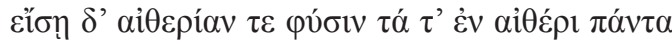

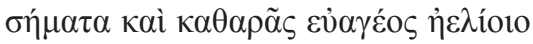

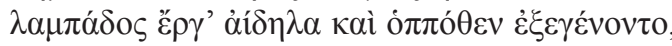

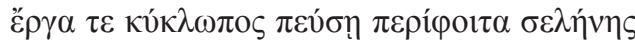

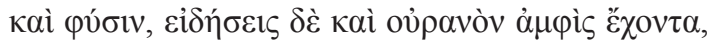

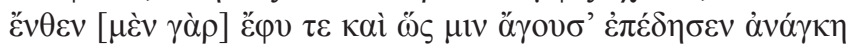

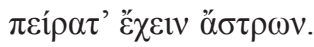

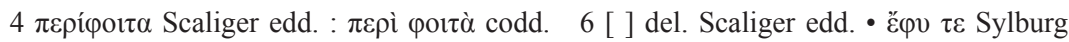

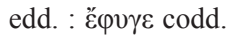

Sabrás la etérea natura y dentro del éter todos los signos que están, y también de la pura y biengobernada luz del Sol la labor invisible, y de dónde nacieron; la labor vagarosa sabrás de Luna la ojirredonda y su naturaleza, y del Cielo que ambos lados separa, dónde nació y cómo la Necesidad que lo lleva lo obligó a guardar el confín de los astros.

Aunque el orden de enumeración no tiene por qué ajustarse a la disposición material de lo enumerado, llama la atención que el orden en que se nombran aquí los cuerpos celestes concuerda minuciosamente con la ordenación descrita por Aecio: en primer lugar, en la zona periférica, el éter y los «signos que están en el éter», es decir, Venus y, probablemente, los demás planetas 22 ; luego siguen, en este orden, el Sol, la Luna (no mencionada por Aecio) y el 'cielo' (oủpavós) obligado a guardar el confín de los astros, ve-

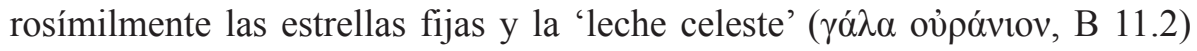
de la Vía Láctea.

Ahora bien, dado lo insólito de semejante disposición, que coloca las estrellas fijas por debajo de las órbitas de los planetas, del Sol y de la Luna, los estudiosos han preferido generalmente restablecer la normalidad astronómica aun en contra de los testimonios, identificando el 'cielo' de B 10.5

el orden en que éstos se suponen efectivamente colocados en el espacio (lo que nos obligaría al absurdo de colocar los astros aún más allá del Olimpo último o confín extremo del mundo; y también la posición de la Luna, más alejada de la Tierra que el Sol, sería extraña y, que yo sepa, sin paralelo en la historia de la astronomía).

${ }^{22}$ Coxon 1986, p. 227; para $\sigma \tilde{\eta} \mu \alpha$ en el sentido de 'astro', cf. Il. XXII 30; E., Hec. 1273; sobre el posible conocimiento de los planetas por Parménides, cf. n. 31 y texto correspondiente. 
con el 'Olimpo último' de B 11.2, i. e., el confín extremo del $\operatorname{cosmos}^{23}$, y

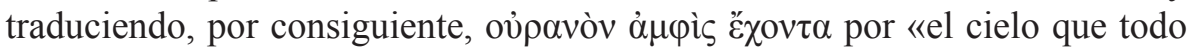
lo abarca». En cuanto a lo primero, sin embargo, es notorio que los griegos, desde Homero y Hesíodo ${ }^{24}$ hasta los pitagóricos ${ }^{25}$, solían distinguir ö $\lambda \nu \mu \pi \mathrm{s}$ y oủ pavós, y así distingue Parménides mismo, en B 11.2, la 'leche celeste'

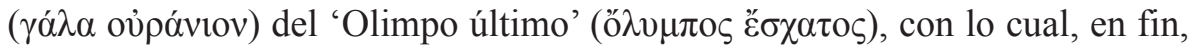
concuerdan unánimemente los testimonios doxográficos ${ }^{26}$. Y en cuanto a la

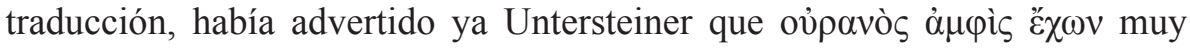
probablemente no es «el cielo que todo lo rodea», sino «que por ambos lados separa o divide», en el mismo sentido en que en Homero las columnas de

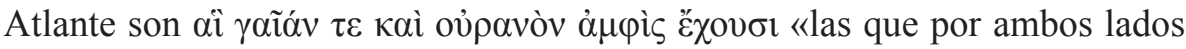
separan la Tierra y el Cielo ${ }^{27}$ : en todo caso, el epíteto sería de lo más pertinente si suponemos que el Cielo separa $\tau \dot{\alpha} \pi \varepsilon \rho i ́ \gamma \varepsilon i \alpha$, el entorno inmediato de la Tierra, por un lado, de la región de la Luna, del Sol y de los planetas, por otro.

Si la verosimilitud de esa ordenación no hubiera de imponérsenos ya por su mera condición de difficilior (pues a duras penas se concibe que los resumidores antiguos hayan trocado por puro descuido el orden acostumbrado de los astros por otro enteramente contrario a todas las nociones ya por entonces establecidas ${ }^{28}$ ), habría de convencernos por lo menos la semejanza con la

${ }^{23}$ Así Tannery 1887/1930, p. 239; Zeller 1892, p. 573 n. 2; Diels 1897, p. 103; Untersteiner 1958, p. CXCII; Tarán 1965, p. 241; Reale, en Zeller, Mondolfo y Reale 1967, p. 262 s.; Heitsch 1974, p. 187; Conche 1996, p. 211.

${ }^{24}$ «The noun ö $\lambda v \mu \pi \mathrm{o}$ in Homer and Hesiod is regularly distinct in sense from oủpavóc, though they may be closely associated», advierte Coxon 1986, p. 231 (cf. Od. XX 103, 113; Hes., Th. 689).

${ }^{25}$ Según Aecio (II 7.7, Dox. 337.11-19), Filolao y los pitagóricos denominaban ö $\lambda v \mu \pi 0 \varsigma$ la región periférica extrema del universo y oủ $\alpha$ avós, por el contrario, la esfera inferior, situada por debajo de la Luna (como oportunamente recuerda Heitsch 1974, p. 187, aunque negando, sin mucho fundamento, que la misma distinción esté presente en Parménides).

${ }^{26}$ Hecho que, si bien evidente, parece haber sido Bollack 1990, p. 51 s., el único en recordar.

${ }^{27}$ Od. I 54; cf. Untersteiner 1958, p. CXCIII n., quien acertadamente traduce, en B 10.5, «che da una parte e dall' altra divide» (ibíd. p. 157); interpretación aceptada también por Bollack 1990, p. 50 («le ciel qui maintient à l' écart, de part et d' autre»).

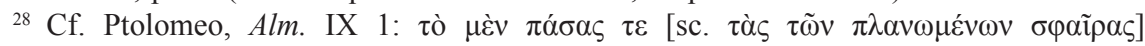

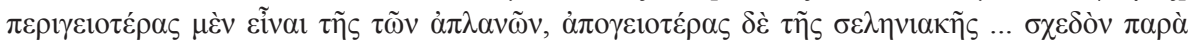

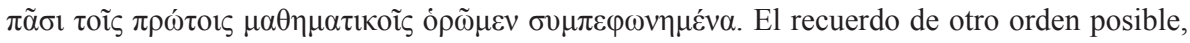


cosmología de Anaximandro, en la cual, según el mismo Aecio (II 15.6, Dox. $345.7-12=12$ A 18), «en lo más alto de todas las cosas está colocado el Sol, después de éste, la Luna, y debajo de éstos las estrellas fijas y los planetas», o, en las palabras de Hipólito (Ref. I $6.5=12$ A 11), «en lo más alto está el Sol, y en lo más bajo los círculos de las estrellas fijas».

El sistema de Anaximandro (Sol-Luna-astros, de la periferia al centro) coincide, pues, puntualmente con el que hemos reconstruido para Parménides (Venus-Sol-Luna-estrellas fijas), salvo en que éste coloca a Venus - y posiblemente los demás planetas - en el extremo de la periferia, más allá del Sol. Sobre las razones de esa innovación no caben más que conjeturas ${ }^{29}$; pero no podemos menos de relacionarla, como hizo ya el propio Aecio, con el descubrimiento de la identidad del lucero vespertino y el del alba, que la tradición atribuye a Parménides ${ }^{30}$ : descubrimiento que equivale a reconocer el desplazamiento anual de Venus respecto al cielo de las estrellas fijas y obliga, por tanto, a asignarle una órbita independiente, análoga a las del Sol y de la Luna. Parménides parece haber sido, por consiguiente, el primer griego que alcanzó a distinguir al menos uno de los planetas de las estrellas fijas, lo cual hace probable que tuviera también alguna noción, cuando menos rudimentaria, del movimiento de los demás planetas ${ }^{31}$, acaso reconocibles en

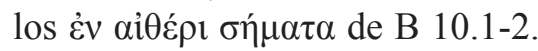

olvidado ya por los astrónomos, debió de sobrevivir ya por entonces tan sólo entre los historiadores de la ciencia como Aecio.

${ }^{29}$ Es notorio que la posición relativa de las órbitas de Venus y Mercurio respecto a la del Sol fue dudosa para los astrónomos griegos aún en tiempos muy posteriores: Ptolomeo, Alm. IX 1, refiere que los «más antiguos» colocaron las esferas de estos dos planetas por debajo de la del Sol, algunos de los posteriores, en cambio, más allá de ésta, y declara finalmente que, dada la ausencia de un paralaje observable que pueda ofrecer un criterio seguro, la cuestión es imposible de decidir con certeza. El criterio aparentemente más sencillo, la duración respectiva de los periodos orbitales aparentes — que había permitido ya en fecha relativamente temprana establecer acertadamente el orden de los planetas exteriores Marte, Júpiter y Saturno- era inoperante en este caso, ya que los griegos, en general, identificaban los periodos sidéreos de Venus y Mercurio con el del Sol (cf. Dicks 1970, p. 186, sobre Eudoxo, y p. 256 n. 345, observando que la distinción era prácticamente imposible de establecer dentro de un sistema geocéntrico). Una útil sinopsis de las diversas ordenaciones de los planetas entre los antiguos ofrece Neugebauer 1975, pp. 690-693; sobre el pasaje de Ptolomeo y la identificación de las escuelas astronómicas aludidas, cf. Burkert 1972, pp. 318-320.

${ }^{30}$ Cf. n. 5.

31 «So we should probably reckon Parmenides the first Greek to identify one of the five planets of Greek astronomy» (Vlastos 1975, p. 45; cf. pp. 102-104, apéndices E-F, sobre 
En todo caso, los sistemas de Anaximandro y de Parménides concuerdan en situar las estrellas fijas por debajo del Sol y de la Luna, a lo menos si damos crédito a las noticias de Aecio, quien por lo demás asegura que la misma ordenación fue defendida aún en fechas mucho más tardías por Metrodoro de Quío, el discípulo de Demócrito, y por Crates $^{32}$. Y lo que es más, esa misma

Anaximandro, Anaxímenes y Alcmeón). Anaximandro, según Aecio (II 15.6, Dox. 345,10-12

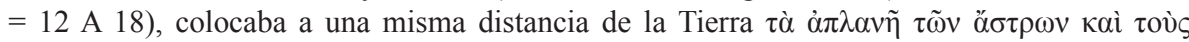
$\pi \lambda \alpha v \eta ́ \tau \alpha \varsigma$, términos que seguramente no pertenecen a Anaximandro sino a Aecio o a su fuente (cf. Kahn 1960, p. 61); cf. Dicks 1970, pp. 33 (en Homero «the planets had not yet been differentiated»), 47 (contra la adscripción de tal distinción a Anaxímenes, intentada por Heath 1913, p. 42 s.), 58 (primera evidencia de un conocimiento de los planetas en Anaxágoras, 59 A 81 = Arist. Mete. I 6, 372b25), 66 (primera mención de los cinco planetas en una noticia sobre Filolao, 44 A 16 = Aecio II 7.7, Dox. 337.15; los nombres por primera vez en Pl., Ti. 38c-d; Epin. 987c). Dicks pasa por alto, sin embargo, los testimonios acerca de la observación de Venus por Parménides, y cuando concluye (p. 167) que «there is no good evidence that [in Greek astronomy] the planets were ever distinguished from the fixed stars before the latter half of the fifth century B.C.», i. e. «in the Philolaic system and perhaps by Democritus» (p. 253 n. 290), parece haber olvidado su propio reconocimiento (p. 58) de que los planetas fueron conocidos, antes de Filolao y Demócrito, por Anaxágoras. En todo lo demás, su valoración de los testimonios me parece del todo coherente con la suposición de que la distinción entre planetas y estrellas fijas haya sido introducida en Grecia por primera vez por Parménides, esto es, una generación antes de Anaxágoras (quien parece ya suponer la existencia de los planetas como un dato establecido) y algo más de medio siglo antes de Demócrito - a quien Dióge-

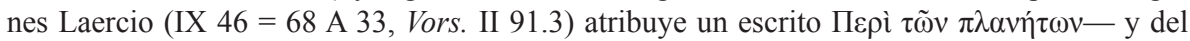
elaborado sistema celestial de Filolao, que presupone una familiaridad ya prolongada con los movimientos planetarios (cf. Burkert 1972, p. 213; acerca de la influencia que la cosmología de Parménides parece haber ejercido sobre la de Filolao, cf. Huffman 1993, p. 261).

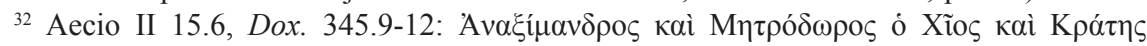

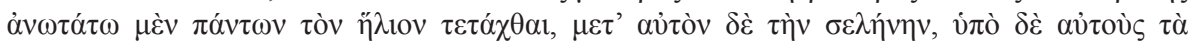

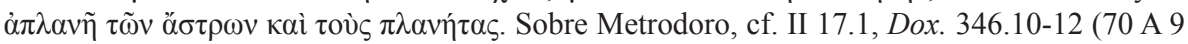

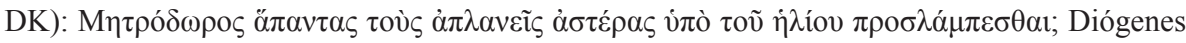
Laercio (IX $33=67$ A 1) atribuye una ordenación lejanamente parecida (Sol-estrellas-LunaTierra) a Leucipo. El Crates mencionado por Aecio no es - como supone erróneamente Kahn 1960, p. 90 n. 2- el cínico de Tebas, que no parece haber mostrado curiosidad alguna por las cuestiones físicas y cosmológicas, sino — como reconoce acertadamente Dicks 1970, p. 90; cf. ibíd. p. 49- el gramático y erudito Crates de Malo o de Pérgamo (fr. 5a Mette), autor de extensos comentarios sobre las supuestas teorías astronómicas de Homero, aunque la atribución de tan arcaica doctrina cosmológica a ese docto filólogo helenístico se deba lo más probablemente a una confusión de Aecio (sobre lo cual cf. Mette 1936, p. 54 s.). Por lo demás, el orden estrellas-Luna-Sol, del centro a la periferia, era familiar a los mitos escatológicos de la tradición irania (v. las referencias en Burkert 1963), aunque una relación directa 
ordenación parece estar supuesta también en el papiro órfico de Derveni, cuyo anónimo autor concibe las estrellas a modo de partículas «que flotan en el aire, lejos unas de otras; pero de día son invisibles, siendo dominadas por el Sol, mientras que de noche son visibles estando ahí, y son dominadas debido a su pequeñez $\rangle^{33}$. Puesto que òń es, en el griego de la edad arcaica, el aire o neblina contenido en la parte inferior del espacio que separa al cielo de la Tierra, hasta las nubes inclusive, mientras que la parte superior, en la que se encuentra el Sol, se llama $\alpha i \theta \eta \rho^{34}$, no me cabe mucha duda de que el Anónimo órfico, al igual que Anaximandro, Parménides y Metrodoro, situaba las estrellas fijas por debajo del Sol y de la Luna ${ }^{35}$.

La semejanza de esta cosmología órfica con la de Parménides se hace más patente aún cuando el Anónimo, tras el paso citado, continúa (Pap. Derveni, col. 25.6-9):

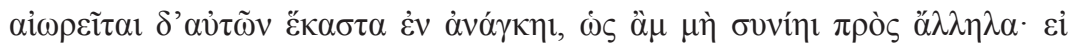

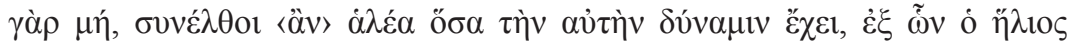

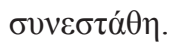

Y están suspendidas cada una de ellas en Necesidad, de manera que no se junten unas con otras; pues si no, confluirían en masa compacta cuantas tienen la misma potencia que aquellas de las que quedó compuesto el Sol.

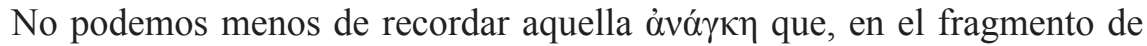
Parménides (B 10.5-7), obliga al cielo a «guardar los límites de los astros»

con el sistema de Anaximandro, como la postula Burkert, no pasa de mera conjetura; otra explicación ofrece Kahn 1960, p. 89 s.

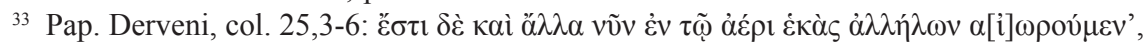

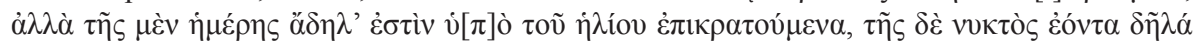

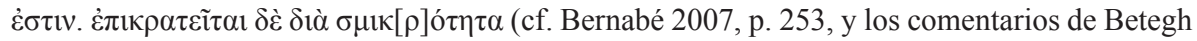
2004, p. 268 s., y Kouremenos, Parássoglou y Tsantsanoglou 2006, p. 267 s.).

${ }_{34}$ Véase, p. ej., Il. XIV 288, sobre el abeto que «a través del aire llegaba al éter» ( $\delta \mathrm{\imath}$ '

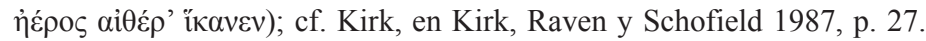

${ }^{35}$ Yerra, por tanto, a mi entender, Betegh 2004, p. 244, cuando afirma: «The author does not tell us anything about the exact location of the stars», y de la indicación de que las estrellas se encuentran «lejos unas de otras» infiere que «it is better if they are closer to the periphery». El Anónimo, por el contrario, dice claramente que las estrellas no se encuentran

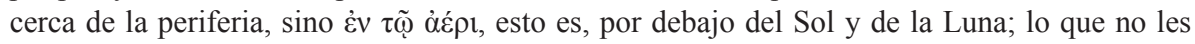
impide, desde luego, estar lo bastante lejos unas de otras, dada su pequeñez ( $\sigma \mu 1 \kappa \rho o ́ \tau \eta \varsigma)$, en la que el Anónimo insiste expresamente. 


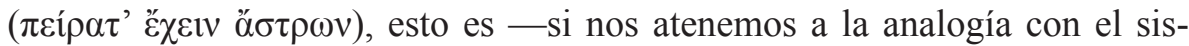
tema órfico-, a mantener las estrellas fijas en sus posiciones respectivas, impidiendo que el elemento ígneo contenido en ellas se derrame y confluya en una sola masa.

Así podemos, en fin, entender algo mejor el pasaje de Cicerón (De nat. d. I $11.28=28$ A 37, Vors. I 224.15-18):

Nam Parmenides quidem commenticium quiddam [sc. deum uoluit esse]: coronae similem efficit - $\sigma \tau \varepsilon \varphi \alpha ́ v \eta v$ appellat - continentem ardorem lucis orbem qui cingit caelum, quem appellat deum; in quo neque figuram diuinam neque sensum quisquam suspicari potest.

similem codd. pl. : simile $\mathrm{OM}^{2}$ ardorem lucis $\mathrm{ACNB}^{2}$ : ardorum lucis $\mathrm{B}^{1}$ : continente [ardore lucis] Davis Diels : ardorum 〈et〉 lucis Plasberg Kranz Untersteiner : ardorum [lucis] Pease Tarán : ardore lucis Conche.

La extrañeza de la construcción cosmológica parece haber dificultado aquí más de lo debido la recta comprensión de la sintaxis por parte de los editores y traductores, empeñados en querer encontrar en las palabras continentem ardorem lucis orbem algo así como «un círculo ininterrumpido de fuego y luz» $\mathrm{o}$ «de fuego luminoso» ${ }^{36}$, pese a que Aecio aclara expresamente que la diosa, si corona o círculo había de ser, era en todo caso del género de las mixtas y no de las de fuego puro. Esa contradicción aparente se resuelve fácilmente con entender que continens ardorem lucis orbis es, sencillamente, un círculo

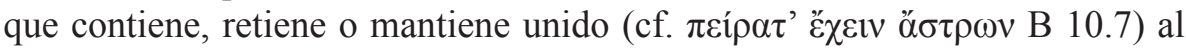
ardor lucis del cielo al que rodea, y que es ígneo ${ }^{37}$ : de ningún modo hemos de suponer que el orbis continens sea él mismo de fuego, como han entendido casi todos los traductores. Así el texto, tal como lo ofrecen la mayoría de los manuscritos, se deja entender sin dificultad, y sin necesidad de corrección alguna, como sigue:

36 «Una circonferenza cioè dotata di un incessante fuoco 〈e〉 di luce», traduce Untersteiner 1958, p. 85; «un orbe de feu-lumière qui ceint le ciel», Conche 1996, p. 220 («de sorte que c'est une couronne de feu sans mélange qui se trouve appelée 'dieu'», en franca contradicción con Aecio, quien declara que la diosa es una de las coronas mixtas); y aun Hölscher 1969, p. 33, a pesar de acoger la lección preferible ardorem, traduce «einen Kreis von Lichtglut».

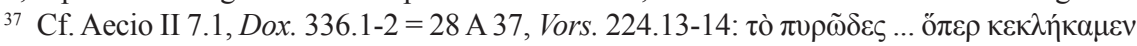

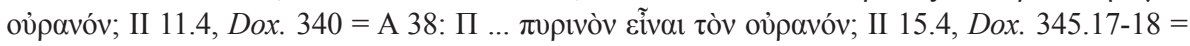

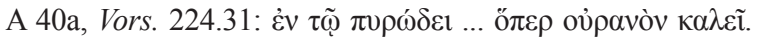


Parménides [quiso que fuera dios] cierto invento suyo: construye un círculo

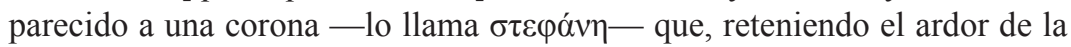
luz, rodea el cielo, y al que llama dios; en lo cual nadie puede sospechar ni condición divina ni sensibilidad alguna.

Así entendido, el testimonio de Cicerón concuerda sin mayor dificultad con el de Aecio, quien identificaba a la diosa gobernadora con la más céntrica de las coronas mixtas. Si suponemos que el orden presente del mundo refleja la estructura pre-cosmogónica de las coronas por lo menos en lo que a la posición de la diosa se refiere (o que así a lo menos lo entendieron los doxógrafos), ésta habrá de encontrarse aproximadamente a medio camino entre la periferia y el centro del universo, esto es, por encima de «lo ígneo que llamamos cielo» (de las estrellas fijas), situado, como Aecio atestigua, por debajo de los planetas, del Sol y de la Luna.

De lo cual resulta, en suma, el siguiente cuadro de conjunto del orden cósmico:

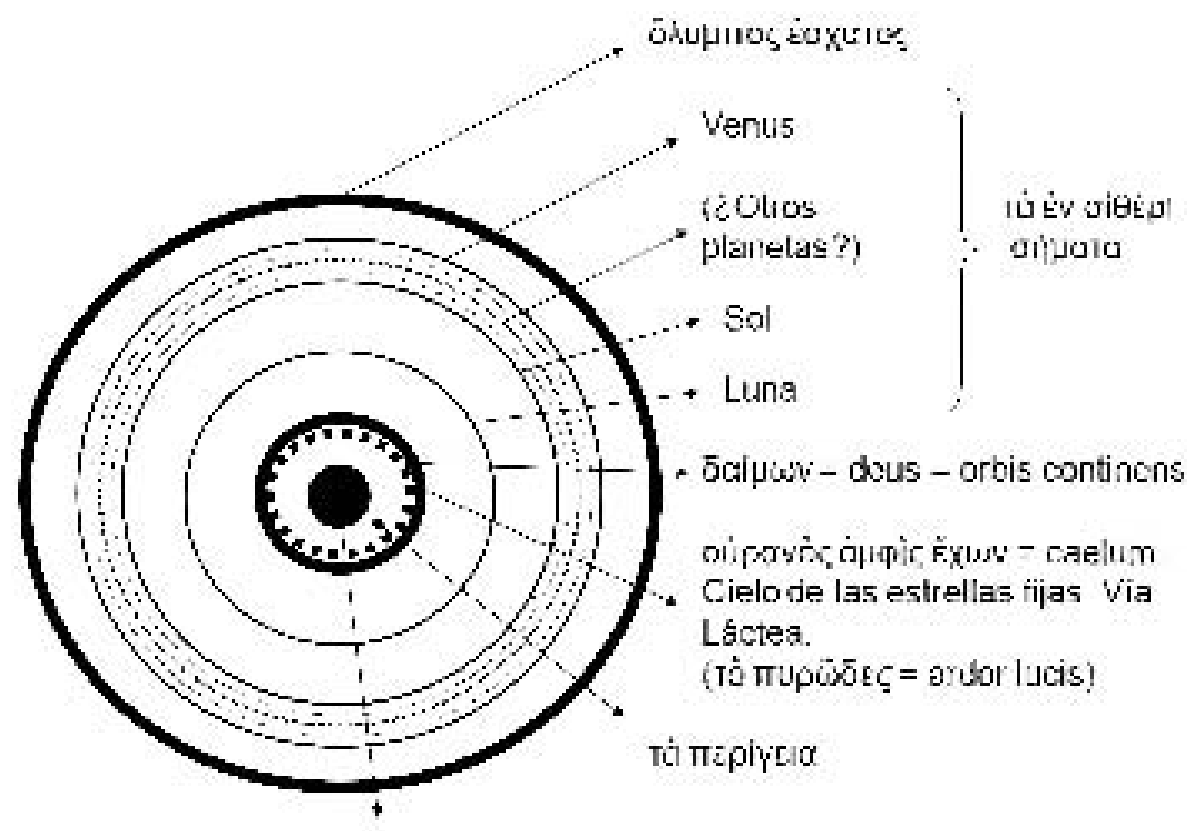

Tierra 


\section{BIBLIOGRAFÍA}

Bernabé, A. 2007: Poetae epici graeci. Testimonia et fragmenta, pars II, fasc. 3, Berlín-Nueva York.

Bernabé, A. y Pérez de Tudela, J. 2007: Parménides. Poema. Fragmentos y tradición textual, Madrid.

Betegh, G. 2004: The Derveni Papyrus. Cosmology, Theology and Interpretation, Cambridge.

Bollack, J. 1990: «La cosmologie parménidéenne de Parménide», en Brague, R. y Courtine, J. F. (eds.), Herméneutique et ontologie. Mélanges en hommage à Pierre Aubenque, París, pp. 17-53.

Bollack, J. 2006: Parménide. De l'Étant au Monde, Lagrasse.

Burkert, W. 1963: «Iranisches bei Anaximandros», RhM 106, pp. 97-134.

- 1972: Lore and Science in Ancient Pythagoreanism, Cambridge.

Burnet, J. 1892, 19304: Early Greek Philosophy, Londres.

Conche, M. 1996: Parménide. Le Poème: Fragments, París.

Coxon, A. H. 1986: The Fragments of Parmenides, Assen.

Dicks, D. R. 1960: The Geographical Fragments of Hipparchus, Londres.

- 1970: Early Greek Astronomy to Aristotle, Londres.

Diels, H. 1897: Parmenides Lehrgedicht, Berlín.

Diels, H. y Kranz, W. 19516: Die Fragmente der Vorsokratiker, Zúrich-Dublín.

Finkelberg, A. 1986: «The Cosmology of Parmenides», AJP 107, pp. 303-317.

- 1997: «Xenophanes' Physics, Parmenides' Doxa and Empedocles' Theory of Cosmogonical Mixture», Hermes 125, pp. 1-16.

Frank, E. 1923: Plato und die sogenannten Pythagoreer, Halle.

Fränkel, H. 1955: Wege und Formen frühgriechischen Denkens, Múnich.

Friedländer, P. 1928: Plato, I: Seinswahrheit und Lebenswirklichkeit, Berlín; cast. 1989, Platón. Verdad del ser y realidad de vida, Madrid.

Furley, D. 1987: The Greek Cosmologists, vol. 1: The formation of the atomic theory and its earliest critics, Cambridge.

García Calvo, A. 1981: Lecturas presocráticas, Madrid; 2001³, Zamora.

Gigon, O. 1945: Der Ursprung der griechischen Philosophie, Basilea.

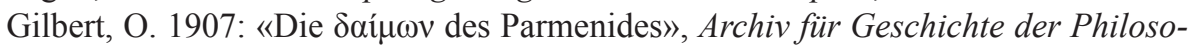
phie 20, pp. 25-45.

Graham, D. W. 2006: Explaining the Cosmos: The Ionian Tradition of Scientific Philosophy, Princeton.

Gundel, W. y Gundel H. 1950: «Planeten bei Griechen und Römern», RE XX 2, cols. 2017-2185.

Guthrie, W. K. C. 1965: A History of Greek Philosophy, vol. 2: The Presocratic Tradition from Parmenides to Democritus, Londres. 
Heath, T. 1913: Aristarchus of Samos. The Ancient Copernicus, Oxford.

Heidel, W. A. 1937: The Frame of the Ancient Greek Maps, with a Discussion of the Discovery of the Sphericity of the Earth, Nueva York.

Heitsch, E. 1974: Parmenides. Die Anfänge der Ontologie, Logik und Naturwissenschaft, Múnich.

Hershbell, J. P. 1972: «Plutarch and Parmenides», GRBS 13, pp. 193-208.

Hölscher, U. 1968: Anfängliches Fragen. Studien zur frühen griechischen Philosophie, Gotinga.

- 1969: Parmenides. Vom Wesen des Seienden, Fráncfort.

Huffman, C. A. 1993: Philolaus of Croton. Pythagorean and Presocratic. A Commentary on the Fragments and Testimonia with Interpretive Essays, Cambridge.

Kahn, C. H. 1960: Anaximander and the Origins of Greek Cosmology, Nueva YorkLondres.

Karsten, S. 1835: Philosophorum Graecorum veterum... Operum Reliquiae, I 2: Parmenidis Eleatae carmina, Ámsterdam.

Kirk, G. S., Raven, J. E. y Schofield, M. 1987: Los filósofos presocráticos, Madrid.

Kouremenos, Th., Parássoglou, G. M. y Tsantsanoglou, K. 2006: The Derveni Papyrus, Florencia.

Lortzing, F. 1902: «Bericht über die griechischen Philosophen vor Sokrates für die Jahre 1876-1897», Jahresbericht über die Fortschritte der Klassischen Altertumswissenschaft 112, pp. 22-322.

Mette, H. J. 1936: Sphairopoiia. Untersuchungen zur Kosmologie des Krates von Pergamon, Múnich.

Morrison, J. S. 1955: «Parmenides and Er», JHS 75, pp. 59-68.

Mullach, F. G. A. 1860: Fragmenta Philosophorum Graecorum, París.

Neugebauer, O. 1975: A History of Ancient Mathematical Astronomy, 3 vols., BerlínHeidelberg-Nueva York.

O'Brien, D. 1968: «Derived Light and Eclipses in the Fifth Century», JHS 88, pp. 114-127.

Pellikaan-Engel, M. 1974: Hesiod and Parmenides, Ámsterdam.

Popper, K. R. 1992: «How the moon might throw some of her light upon the two ways of Parmenides», $C Q 42$, pp. 12-19.

- 1998: The World of Parmenides. Essays on the Presocratic Enlightenment, Londres-Nueva York.

Reinhardt, K. 1916: Parmenides und die Geschichte der griechischen Philosophie, Fráncfort.

Sider, D. 1979: "Confirmation of Two "Conjectures" in the Presocratics: Parmenides B 12 and Anaxagoras B 15», Phoenix 33, pp. 67-69. 
Steele, L. D. 2002: «Mesopotamian elements in the proem of Parmenides? Correspondences between the sun-gods Helios and Shamash», CQ 52, pp. 583-588.

Susemihl, F. 1899: «Zum zweiten Theile des Parmenides», Philologus 58, pp. 205214.

Tannery, P. 1887/1930: Pour l'histoire de la science hellène, París.

Tarán, L. 1965: Parmenides. A Text with Translation, Commentary and Critical Essays, Princeton.

Untersteiner, M. 1958: Parmenide. Testimonianze e frammenti, Florencia.

Verdenius, W. J. 1964²: Parmenides. Some Comments on his Poem, Ámsterdam.

Vlastos, G. 1975: Plato's Universe, Oxford.

Wöhrle, G. 1995: «Wer entdeckte die Quelle des Mondlichts?», Hermes 123, pp. 244-247.

Zeller, E. 18925: Die Philosophie der Griechen in ihrer geschichtlichen Entwicklung, Leipzig.

Zeller, E., Mondolfo, R. y Reale, G. 1967: La filosofia dei greci nel suo sviluppo storico, I.III: Eleati, Florencia.

Zhmud, L. 1997: Wissenschaft, Philosophie und Religion im frühen Pythagoreismus, Berlín. 